Sharif University of Technology
Scientia Iranica
SCIENTIA
I RAN I CA
http://scientiairanica.sharif.edu

\title{
Usability of arc fault circuit interrupters with network function
}

\author{
H.-S. Kong ${ }^{a}$ and W.-J. Ra ${ }^{\mathbf{b}, *}$ \\ a. Department of Fire Safety, Kyungil University, 38428, 50 Gamasilgil, Hayangup Gyeongsan Gyeongbuk, South Korea. \\ b. Hetko Inc., Gayang-Technotown \#602-2, 07531, 217 Heojun-ro, Gangseo-Gu Seoul, South Korea.
}

Received 28 August 2017; accepted 3 March 2018

\author{
KEYWORDS \\ Network; \\ Arc Fault Circuit \\ Interrupter (AFCI); \\ Electricity \\ management; \\ External monitoring; \\ Interruption cause \\ analysis.
}

\begin{abstract}
The existing arc fault circuit interrupters have the function of interrupting overloads, ground fault, and arc fault; however, they have neither the monitoring function to allow external monitoring nor the notification function to notify the fire safety manager. This study investigates the arc fault circuit interrupters with the network function, which have not been studied so far. We intend to install these arc fault circuit interrupters in places such as server rooms, pigsties, chicken farms, markets, cultural assets, skyscrapers, and factories, where large loss may occur if the fire safety managers do not recognize the electricity shutdown, in order to increase the efficiency of electricity management. If an overload, a short circuit, or an arc is detected when power is supplied to the load, the microprocessor generates a trip signal and cuts off the power by this trip signal. This situation is monitored in real time by external monitoring and notified to the fire safety manager. The fire safety manager can immediately recognize the situation when the arc fault circuit interrupter interrupts the circuit and takes the necessary action to manage the electricity efficiently.

(C) 2020 Sharif University of Technology. All rights reserved.
\end{abstract}

\section{Introduction}

According to the statistics of Korea Electric Safety Corporation in 2015, 7,500 9,000 electric fires occur each year, accounting for about $20 \%$ of the total 40,000 $\sim 45,000$ fire counts in Korea. In terms of the causes of electric fires, electric sparks (arc faults), accounting for $78 \%$ of the total, are the main cause of electrical fires, followed by overloads, accounting for $10.2 \%$, and ground fault, accounting for $3.9 \%$, respectively, while other causes account for $7.8 \%$ of the electric fires [1]. Therefore, it is necessary to detect and interrupt the electric spark effectively in order to prevent electric fire. The electric spark can be due to various reasons

\footnotetext{
*. Corresponding author.

E-mail address: woong-jae_ra@uoel.uk (W.-J. Ra)
}

doi: $10.24200 /$ sci.2018.5086.1088 such as deterioration of the electric wire, defective electric product, and faulty contact of the electric wire [2]. In case of the electric spark, the temperature rises instantaneously from several thousands to tens of thousands degrees Celsius. It is very dangerous as it can cause fire in a few seconds. In the arc fire simulation results of the National Institute of Standards and Technology (NIST), it was observed that one room would burn in 40 seconds after leaving an arc fault without interrupting it [3]. It is necessary to introduce arc fault circuit interrupters in Korea to prevent fire caused by electric sparks in advance. It is possible to secure safe electricity management if we can externally monitor the identification and analysis of the interruption causes through the network.

Previous studies on arc fault or arc fault circuit interrupters include the work of Qi et al. (2017). They provided an in-depth analysis of the parameters for Discrete Wavelet Transform (DWT) applied to 
detection of arc faults that could greatly improve arc defect detection performance. In their study, the method of optimal parameters estimation for discrete wavelet transform was utilized for arc fault detection in low-voltage residential power networks. The influence of three parameters was investigated: the choice of mother wavelet, level of decomposition, and sampling frequency. A performance criterion was defined and used to compare the influences of 550 combinations of these three parameters on the arc fault detection performance for different loads in two household appliances. The study showed that the choice of these three parameters greatly influenced the arc fault detection performance [3].

Guo et al. (2016) built a series arc fault generator based on UL1699 in their study. Experiments were carried out under different load conditions. Loop current waveforms with and without series arc fault were obtained. Firstly, the current signal was decomposed and reconstructed by wavelet transform. Then, the irregular degrees of signals in each frequency band were quantified with approximate entropy algorithm and the feature vectors of current signals were obtained. Finally, all the feature vectors were used as input variables to Support Vector Machine (SVM). The series arc fault could be identified by classifying those feature vectors with SVM. It was shown that the feature vectors obtained by wavelet approximate entropy algorithm could diagnose series arc fault [4].

Chae et al. (2016) presented a detection algorithm for series DC arc faults to improve safety issues in DC microgrids in their research. To identify series arc faults accurately and quickly in DC microgrids, a series DC arc fault detection algorithm using relative magnitude comparison was proposed. The proposed algorithm detected the time of occurrence of an arc fault based on the magnitudes of the load current in both the time and frequency domains, simultaneously. The algorithm accurately worked for a DC microgrid with multiple switching converters, as it relied only on relative current information [5].

Jovanovic et al. (2016) presented a novel method based on a single-phase Active Power Filter (APF) for series arc faults detection in an AC electrical installation. The APF's reference current was used as the starting point for their method to test a large variety of loads. The proposed method was validated at the simulation level using first the MATLAB software and then the Hardware-In-the-Loop (HIL) approach experimentally with an FPGA Altera Stratix III prototyping board. The results obtained in this work showed that series arc faults could be successfully detected with an APF only by updating its digital control with the arc fault detection functionality, instead of designing an arc-fault detection-specific device from the very beginning [6].
Liu et al. (2016) used the approach of radial basis function neural network (RBFNN) to identify the occurrence of serial arc faults. The Discrete Wavelet Transform (DWT) was employed to obtain the time-frequency domain characteristics of line current waveforms for representing the serial arc fault patterns. This study compared the results with two other methods in Detection of Sub-spectrum Energy (DSE) and High Frequency Detection by Wavelet Transform (HFDWT). It was observed that RBFNN had better ability than DSE and HFDWT in the detection of serial arc faults [7].

Hatton et al. (2016) reported the results of a project to develop a DC Arc Generator (AG) suitable for use in the development and testing of DC arc fault detectors [8].

Zhu et al. (2016) discussed a testbed that had been developed for the purpose of testing arc fault detectors in a laboratory environment using precise reproduction or replay of pre-recorded arc signals. The testbed was capable of replaying both the arc signature and the noise from the power electronic circuits at proper amplitude to represent real-world conditions. Utilization of such a testbed would facilitate the study of reliable detection algorithms [9].

Zhu et al. (2016) reported the results of development of a real-time arc fault detection technique that was built as a wavelet decomposition based arc detector using a TI C2000 platform DSP. The arc fault detector was tested on a composite arc signal constructed from recordings of real-world inverter noise and real-world arc events replayed through a high-fidelity testbed to compare the abilities so that the exclusive inverter signals could be differentiated from inverter plus arcing signals. The results demonstrated that the wavelet decomposition and arc discrimination algorithms could be implemented in real time on a low-cost DSP [10].

Wang and Balog (2016) presented an effective method based on wavelet transform and Support Vector Machines (SVM) for detection of arc faults in DC PV systems. Because of its advantages in timefrequency signal processing, wavelet transform was applied to extract the characteristic features from system voltage/current signals. SVM was then used to identify arc faults. The performance of the proposed technique was compared with traditional Fourier transform based approaches [11].

Zhao et al. (2016) first introduced the discharge characteristics and classification of arc faults. Then, the research status of AC AFD methods was summarized. Also, this paper analyzed the advantages and disadvantages of the methods and proposed a new method for arc fault detection based on arc fault difference signal analysis and wavelet transform. The fundamental waves of the collected current signals were removed and then, the obtained difference signal 
was analyzed by the stationary wavelet transform in MATLAB. Afterwards, the modulus maxima of a layer of detail waveform were selected as the feature for detection. The experimental results showed that this method could improve the accuracy of fault arc detection [12].

Liu et al. (2016) proposed a method based on Hilbert-Huang Transform (HHT) and Artificial Neural Networks (ANN) for AC SSPC arc fault detection. Numerical simulation results together with discussions were provided, which indicated the effectiveness of the proposed fault detection method. Specifically, HilbertHuang transform based multi-resolution analysis was adopted to obtain the features of the AC SSPC arc current in the measured signal and artificial neural networks were adopted to identify the faults based on the extracted features [13].

Johnson et al. (2011) stated that manufacturers were developing new Arc Fault Circuit Interrupters (AFCIs). The Distributed Energy Technologies Laboratory (DETL) at Sandia National Laboratories (SNL) used multiple reconfigurable arrays with a variety of module technologies, inverters, and Balance Of System (BOS) components to characterize new Photovoltaic (PV) DC AFCIs and Arc Fault Detectors (AFDs). Detection capabilities, characteristics, and nuisance tripping avoidance of the device were the primary purpose of the testing. The results showed that significant noise was injected into the array from the inverter, but AFCI functionality of the device was generally stable [14].

Strobl and Meckler (2010), through the analysis of the measured signals in time and frequency domains, showed that parallel arcing involved significant changes in the current at the primary side of the converter and was therefore easily detectable. Serial arc faults, however, could not usually be detected by a lowfrequency analysis of current and voltage signals due to the specific characteristic curve of the photovoltaic modules, the control concept of the converter for maximum power tracking, and the possible change in solar irradiance [15].

Yao et al. (2012) designed an experimental system to study the characteristics of series DC arc. Different tests were conducted in order to determine the influence of different factors, such as gap length, current, etc., on the arc [16].

Johnson and Armijo (2014) discussed the differences between establishing and sustaining arc-faults for a number of different test configurations, compared the variability of arc-fault spectral content for each test, and analyzed the evolution of the RF signature over the duration of the fault. Their ultimate goal was to determine the most repeatable 'worst case' tests for adoption by UL [17].

Sidhu et al. (2002) described the development of a multi-sensor device based on four different physical phenomena for reliable detection of low-level arcing faults in metal-clad switchgear. The device could also be applied to the detection of arcing in power electronic drives, dry-type transformers, gas insulated switchgear, generator bus-ducts, and other metal-clad electrical apparatuses [18].

Chen and $\mathrm{Li}$ (2016) aimed at providing a joint detection method for Arc Fault Circuit Interrupters (AFCI) serving smart micro grid. In this paper, two methods to bring PV series arc fault into the PV system were recorded by Intensified Charge-Coupled Device (ICCD). A relatively satisfying joint algorithm based on the two proposed detection variables was put forward to prevent unwanted nuisance trips in the system transient process. To constantly fit varying electric signals in the PV system, this detection algorithm also adopted dynamic threshold value [19].

Analysis of the existing research studies shows that most of them suggest methods for reducing arc fault and testing performance of arc fault circuit interrupters; however, there is no study on arc fault circuit interrupters with the network function. Therefore, this study aims to improve the performance of arc fault circuit interrupter management by introducing network function into the existing arc fault circuit interrupters, considering the case of places where large loss may occur if the fire safety manager does not recognize the electric shutdown quickly, e.g., server rooms.

\section{Structure of an existing AFCI without the network function}

\subsection{Appearance and block diagram}

Figure 1(a) shows the appearance of an arc fault circuit interrupter. The test button is located on the front side of the arc fault circuit interrupter. Figure 1(b) represents the block diagram of the arc fault circuit interrupter. The arc detection unit, the overload detection unit, and the short circuit detection unit detect arc fault, overloads, and ground fault. They send the detection signals to the microprocessor. The microprocessor receives the signals and sends them to the trip function unit to turn off the power [20].

\subsection{Operation mechanism}

As shown in Figure 2, when a load is connected to the arc fault circuit interrupter and power is supplied, real-time monitoring of dangerous signals for electrical hazard factors such as arc fault, overloads, and ground fault is performed. If a dangerous signal such as an overload, a short circuit, or an arc is detected while supplying power to the load, a trip signal is generated to shut off the power.

As mentioned above, the existing arc fault circuit interrupters have the functionality of interrupting 


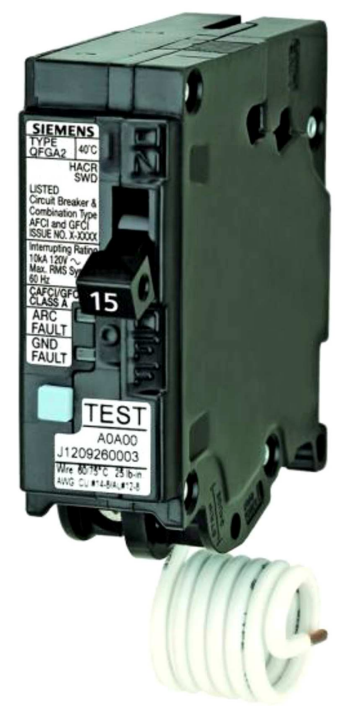

(a) Appearance [21]

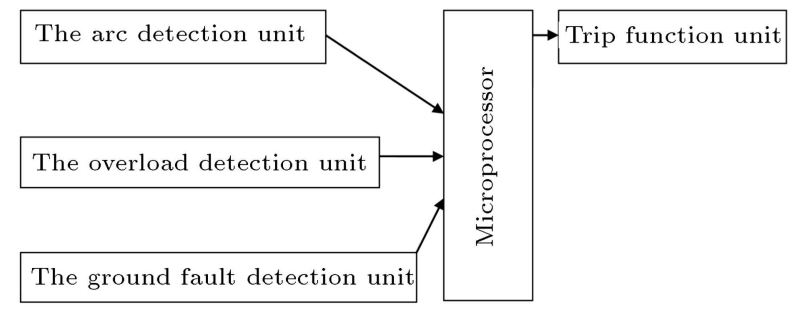

(b) Block diagram

Figure 1. Structure of the existing AFCI without the network function.

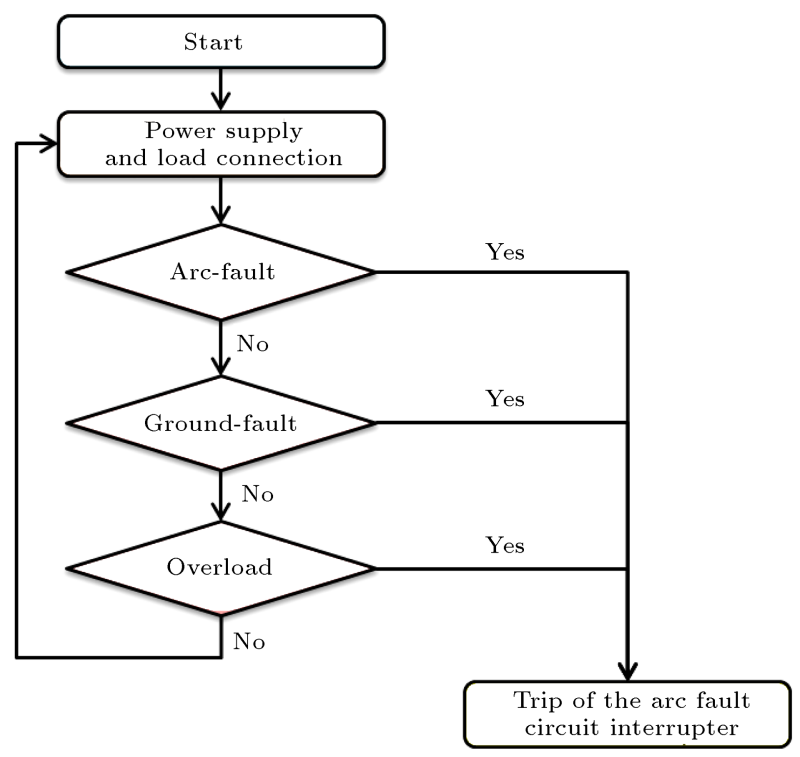

Figure 2. Operation mechanism of the existing AFCI without the network function.

overloads, ground fault, and arc fault; however, none of them has the monitoring function to allow for external monitoring or the notification function to notify the fire safety manager.

\section{Structure of an AFCI with the network function}

\subsection{Block diagram and circuit diagram}

Figure 3(a) shows the appearance of an arc fault circuit interrupter with the network function. The network connection unit is located at the bottom of the arc fault circuit interrupter.

Figure 3(b) is the block diagram of the arc fault circuit interrupter. The arc detection unit, the overload detection unit, and the short circuit detection unit detect arc fault, overloads, and ground fault. They send the detection signals to the microprocessor. The microprocessor receives the signals and sends them to the trip function unit to turn off the power. At the same time, the microprocessor sends the signals to the network unit.

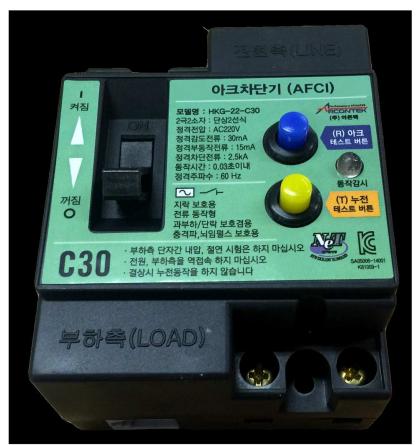

The network connection unit

(a) Appearance

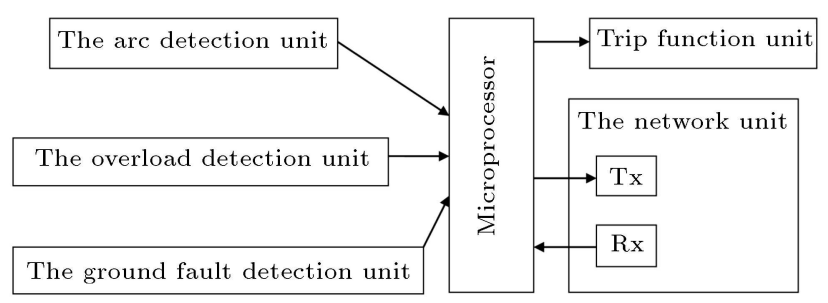

(b) Block diagram

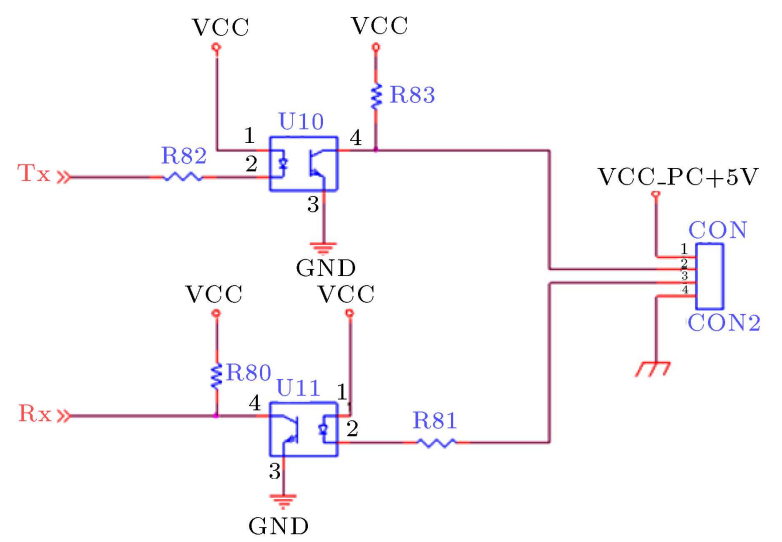

(c) Detailed circuit diagram of the network unit

Figure 3. AFCI with the network function. 
Figure $3(\mathrm{c})$ is a detailed circuit diagram of the network unit. When the network unit receives signals through its $\mathrm{Tx}$ and $\mathrm{Rx}$ terminals, its output unit generates the RS232 signals at the TTL level. Generally, RS232 is configured with its GND set on "Common" and its Tx and Rx set to select "High" to send and receive signals. The signals from the microprocessor are converted by the insulation elements, i.e., photo couplers (U10 and U11), enabling the communication of signals without damaging the external network unit connected to the arc fault circuit interrupter.

\subsection{Operation mechanism}

As shown in Figure 4, when the load is connected to the arc fault circuit interrupter and the arc fault circuit interrupter is turned on by supplying the power, self-diagnosis is carried out to see whether the arc fault circuit interrupter operates normally. If the arc fault circuit interrupter does not operate normally, an abnormal signal is generated. If the arc fault circuit interrupter operates normally, overloads, ground fault, and arc fault are monitored in real time. If an overload, a short circuit, or an arc is detected while power is supplied to the load, the arc fault circuit interrupter is tripped to cut off the power and generate a trip signal [21].

This situation is monitored in real time by exter- nal monitoring and notified to the fire safety manager. The fire safety manager can immediately recognize the situation when the arc fault circuit interrupter interrupts the circuit and take the necessary action to manage the electricity efficiently. The arc fault circuit interrupters with the network function can be effectively used in server rooms, pigsties, chicken farms, markets, cultural assets, skyscrapers, factories, etc. that require real-time monitoring of the arc fault circuit interrupters.

Table 1 shows the comparison between the existing arc fault circuit interrupter and the arc fault circuit interrupter with the network function.

\section{Conclusions}

An arc fault circuit interrupter with the network function was equipped with the communication function by a microprocessor to determine whether the cause of the interruption was an overload, an arc, or a short circuit and transmit and notify the result to the management system of a remote place through the network. The arc fault circuit interrupter allows the circuit to be interrupted by remote control if necessary. This arc fault circuit interrupter prevents both electrical accidents and fires more accurately and supports the communication function for the network. Through the network, the external monitoring system

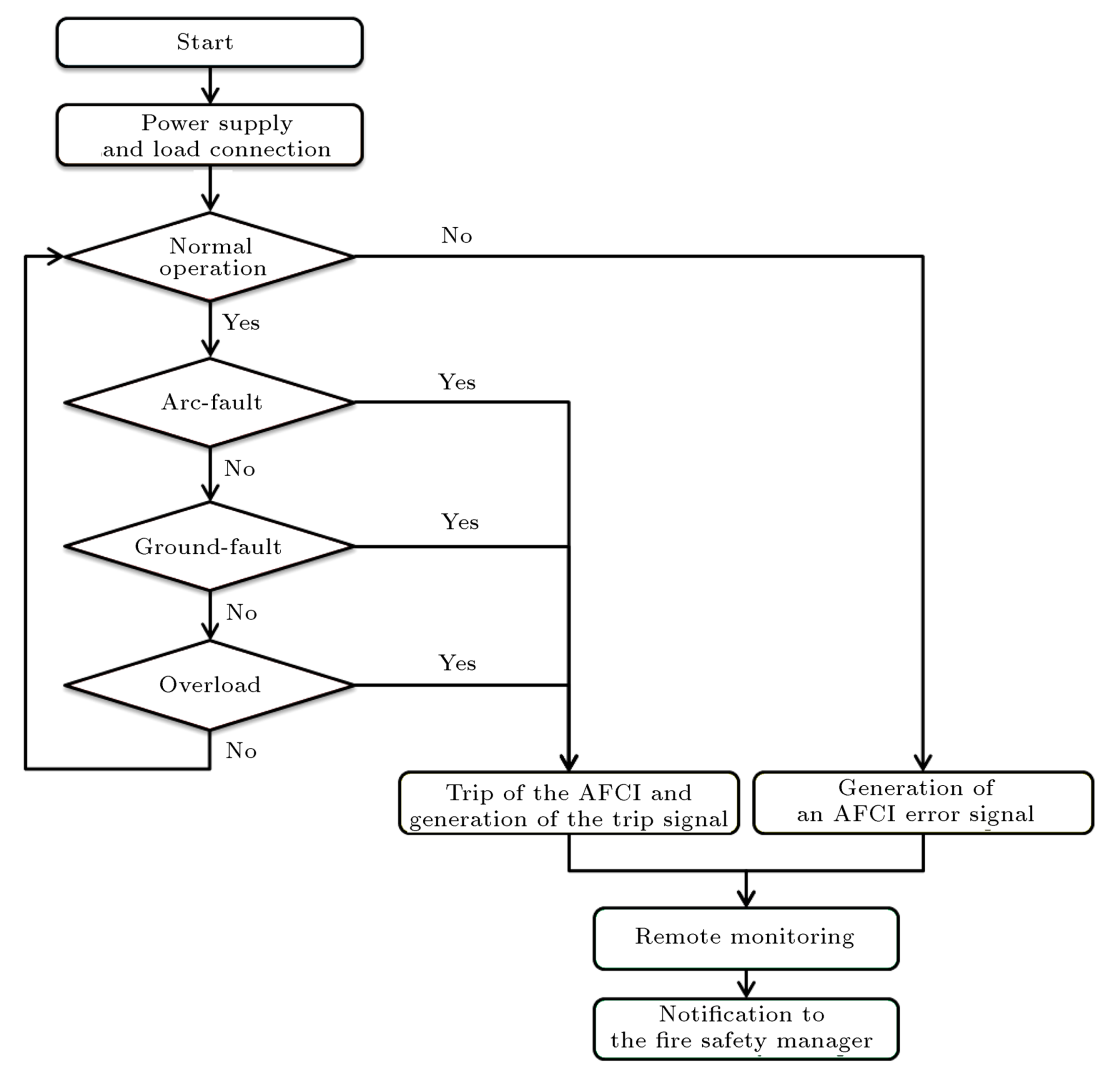

Figure 4. Operation mechanism of the AFCI with the network function. 
Table 1. Comparison between AFCIs with and without network function.

\begin{tabular}{lcc}
\hline & Existing AFCI & $\begin{array}{c}\text { AFCI with network } \\
\text { function }\end{array}$ \\
\hline Function of interrupting overloads & Yes & Yes \\
Function of interrupting ground fault & Yes & Yes \\
Function of interrupting arc fault & Yes & Yes \\
Function of external monitoring & No & Yes \\
Function of remote interruption & No & Yes \\
\hline
\end{tabular}

can identify and analyze the interruption causes and improve the efficiency of electricity management.

Now, the installation of an arc fault circuit interrupter to prevent electric fire must be compulsory, not an option. Especially, it is necessary to actively introduce the arc fault circuit interrupters based on the network because they can be used in places where realtime monitoring of the electricity is required; moreover, electricity management can be efficiently performed by them.

\section{References}

1. Kwangsu, K. "Korea electric safety corporation", 2015 Electric Disaster Statistical Analysis, pp. 112-114 (2016).

2. Kim, J.-H., Lee, D.-S., and Lee, H.-S. "Design of a door hinge with the function of preventing a door from getting closed", In Conference Proceedings of Ergonomics Society of Korea, pp. 170-171 (2013).

3. National Institute of Standards and Technology <http://www.nist.gov> (Oct. 10 2017).

4. Qi, P., Jovanovic, S., Lezama, J., and Schweitzer, P. "Discrete wavelet transform optimal parameters estimation for arc fault detection in low-voltage residential power networks", Electric Power Systems Research, 143, pp. 130-139 (2017).

5. Guo, F., Li, K., Chen, C., Liu, Y., Wang, X., and Wang, Z. "Series arc fault identification method based on wavelet approximate entropy", Transactions of China Electrotechnical Society, 31(24), pp. 164-172 (2016).

6. Chae, S., Park, J., and Oh, S. "Series DC arc fault detection algorithm for DC microgrids using relative magnitude comparison", IEEE Journal of Emerging and Selected Topics in Power Electronics, 4(4), pp. 1270-1278 (2016).

7. Jovanovic, S., Chahid, A., Lezama, J., and Schweitzer, P. "Shunt active power filter-based approach for arc fault detection", Electric Power Systems Research, 141, pp. 11-21 (2016).

8. Liu, Y.-W., Wu, C.-J., and Wang, Y.-C. "Detection of serial arc fault on low-voltage indoor power lines by using radial basis function neural network", International Journal of Electrical Power and Energy Systems, 83, pp. 149-157 (2016).
9. Hatton, P.C., Bathaniah, M., Wang, Z., and Balog, R.S. "Arc generator for photovoltaic arc fault detector testing”, In IEEE Photovoltaic Specialists Conference, IEEE, USA (2016).

10. Zhu, H., Wang, Z., McConnell, S., Hatton, P.C., Balog, R.S., and Johnson, J. "High fidelity 'replay' arc fault detection testbed", In IEEE Photovoltaic Specialists Conference, IEEE, USA (2016).

11. Zhu, H., Wang, Z., and Balog, R.S. "Real time arc fault detection in PV systems using wavelet decomposition", In IEEE Photovoltaic Specialists Conference, IEEE, USA (2016).

12. Wang, Z. and Balog, R.S. "Arc fault and flash detection in photovoltaic systems using wavelet transform and support vector machines", In IEEE Photovoltaic Specialists Conference, IEEE, USA (2016).

13. Zhao, Y., Zhang, X., Dong, Y., and Li, W. "Characteristics analysis and detection of $\mathrm{AC}$ arc fault in SSPC based on wavelet transform", In AUS 2016-2016 IEEE/CSAA International Conference on Aircraft Utility Systems, pp. 476-477 (2016). https://ieeexplore.ieee.org/document/7748097/metric -s \#metrics

14. Liu, W., Zhang, X., Ji, R., Dong, Y., and Li, W. "Arc fault detection for AC SSPC in MEA with HHT and ANN", In AUS 2016-2016 IEEE/CSAA International Conference on Aircraft Utility Systems, pp. 7-8 (2016). https://ieeexplore.ieee.org/abstract/document/ 7748012

15. Johnson, J., Pahl, B., Luebke, C., Pier, T., Miller, T., Strauch, J., Kuszmaul, S., and Bower, W. "Photovoltaic DC arc fault detector testing at Sandia national laboratories", In Photovoltaic Specialists Conference (PVSC), IEEE, USA (2011).

16. Strobl, C. and Meckler, P. "Arc faults in photovoltaic systems, electrical contacts (HOLM)", In 2010 Proceedings of the 56th IEEE Holm Conference on IEEE, USA (2010).

17. Yao, X., Herrera, L., Huang, Y., and Wang, J. "The detection of DC arc fault: experimental study and fault recognition", In Applied Power Electronics Conference and Exposition (APEC), 2012 Twenty-Seventh Annual IEEE, IEEE, USA (2012). 
18. Johnson, J. and Armijo, K. "Parametric study of PV arc-fault generation methods and analysis of conducted DC spectrum", In Photovoltaic Specialist Conference (PVSC), IEEE, USA (2014).

19. Sidhu, T.S., Sagoo, G.S., and Sachdev, M.S. "Multisensor secondary device for detection of low-level arcing faults in metal-clad MCC switchgear panel", IEEE Transactions on Power Delivery, 17(1), pp. 129130 (2002).

20. Chen, S. and Li, X. "PV series arc fault recognition under different working conditions with joint detection method, electrical contacts", In Proceedings of the Annual Holm Conference on Electrical Contacts, IEEE, USA (2016).

21. Dual Function AFCI/GFCI Circuit Breaker <http:// w3.usa.siemens.com/powerdistribution/us/en/product -portfolio/circuit-breakers/residential-circuit-breakers /pages/dual-function.aspx> (Nov. 11 2017).

\section{Biographies}

Ha-Sung Kong majored in Disaster Science in the Graduate School of University of Seoul. His main interests are firefighting facilities, safety policies, disaster management, and firefighting qualification systems among others. He currently works in the Department of Fire Safety of Kyungil University as an Associate Professor.

Woong-Jae Ra majored in Electrical \& Electronic Engineering and Business Administration at Yonsei University. He worked in KT Corporation (Korea Telecom) and Accenture PLC, and performed various IT and energy related projects. Currently, he is the CEO of Arcontek Co., Ltd., which is a leading professional manufacturer of AFCI (Arc Fault Circuit Interrupter) in Korea. 